\title{
PENERAPAN RUMAH PANTAS DITEMPATI BAGI MASYARAKAT KURANG MAMPU DI DESA KAREHKEL KECAMATAN LEUWILIANG KABUPATEN BOGOR
}

\author{
Syaiful $^{1}$, Resti Anggraini ${ }^{2}$, Fuad Hakim ${ }^{2}$ \\ syaiful@ft.uika-bogor.ac.id \\ Dosen Fakultas Teknik ${ }^{1}$, Mahasiswa KKN Kelompok 55 Tahun $2018^{2}$
}

\begin{abstract}
ABSTRAK
Peningkatan program rumah pantas untuk dihuni adalah program rumah sehat dengan kualitas material yang digunakan, komponen penataan ruang, pencahayaan, kualitas udara dan ventilasi. Selanjutnya tersedianya sumber air layak minum, vector penyakit, pembuangan limbah dan kepadatan hunian. Rata-rata tingkat kepadatan hunian di desa Karehkel masih rendah jadi memungkinkan di adakan penyampaian tentang rumah layak huni. Metode pendekatan yang dipakai dalam program rumah pantas ditempati adalah (1) pendekatan di dalam musholla dan masjid serta pengajian; (2) pendekatan kekerabatan dalam arisan; (3) pendekatan sosial kemasyarakatan. Hasil yang didapatkan untuk masyarakat kurang mampu adalah bertambahnya pengetahuan masyarakat dalam mengelola rumah sehat dan siap untuk ditempati. Diharapkan adanya proses perubahan perilaku di lingkungan masyarakat kurang mampu agar mereka memahami, mengetahui dan mampu melakukan perubahan demi tercapainya masyarakat sehat dan adil makmur dalam menghuni rumah yang sangat layak.
\end{abstract}

Kata Kunci : Kepadatan penduduk, rumah layak huni, masyarakat kurang mampu.

\section{PENDAHULUAN}

\section{Latar Belakang}

Tempat tinggal yang diistilahkan dengan rumah adalah dihuni oleh masyarakat kita di Indonesia merupakan bagian terpenting dalam pemenuhan kebutuhan hidup tentang papan. Dimanapun manusia mesti membutuhkan tempat berlindung. Selain tempat berlindung dari gangguan dari luar seperti cuaca ekstrim baik itu hujan panas maupun badai juga sangat dibutuhkan fungsi tempat berlindung itu dari serangan hewan atau binatang buas. Keguanaan lain adalh tempat berlindung itu berfungsi sebagai tempat melepas rasa capek dan untuk mengumpulkan semua anggota keluarga baik dari keluarga terdekat maupun jauh dan tidak menutup kemungkinan rumah berfungsi tempat diadakanya acara-acara kekeluargaan yang bersifat lebih luas dari arti sebenarnya. Selain itu, rumah juga merupakan status lambang sosial. (Nastiti L, 2010; Syaiful, 2005; Syaiful, Elvira Y, 2017).

Perumahan merupakan juga merupakan tempat yang sangat penting dalam melihat tingkat status sosial seseorang. Dalam membuat sebuah rumah harus mengacu kedalam kaidah-kaidah yang sudah ditetapkan dan dipedomani sebagai acuan. Adapun acuan dasar dalam membangun rumah adalah harus memenuhi standar tertentu seperti harus bersih dari lingkungan yang kurang sehat, 
material yang digunakan juga memenhi standar SNI, serta syarat-syarat teknis yang tentu dapat dipertanggungjawabkan dalam segi teknisnya (Keputusan Kementerian Kesehatan Republik Indonesia, 1999; Undang-undang Nomor 23, 1992).

Perumahan yang disebut layak dan siap huni itu adalah dapat membuat aman dan nyaman penghuninyadan merupakan arena interaksi antara seluruh keluarga yang ada di dalam rumah tersebut (Keputusan Kementerian Kesehatan Republik Indonesia, 1999; Wijaya M, 2010). Menurut WHO, 2001, rumah adalah perpaduan antara bentuk nyata struktur bangunan perumahan dengan segi estetis maupun kesehatan yang ditampilkan dalam bentuk tampak. Adapun tampak yang dibutuhkan dalam segi teknis adalah memenuhi syarat tampak depan, tampak samping, tampak kiri dan tampak kanan. Juga diperlukan potongan yang membentuk ruangan yang terbentuk dari jenis perumahan maupun ukuran-ukuran yang ditampilkan dalam bentuk fisik struktur banguna perumahan tersebut (Komisi WHO Mengenai Kesehatan dan Lingkungan, 2001; Kurniasih D, 2011; Nurwati N, 2008).

\section{Rumah Sehat yang mendukung}

Maksud dari perumahan yang siap untuk dihuni adalah rumah sehat dengan konstruksi yang kokoh untuk bisa berinteraksi antar penghuni, antar warga dan antar masyarakat sekitar dengan baik dan benar. Unsur ini meliputi tentang pembinaan keluarga yang menumbuhkan kehidupan sehat secara terstruktur untuk semua penghuninya (Kementerian Pekerjaan Umum dan Perumahan Rakyat (PUPR), 2002). Perumahan siap ditempati harus mendukung program pemerintah bahwa 3 konsep harus terpenuhi agar menjadi acuan seperti aman nyaman dan terkendali.

\section{PENGERTIAN RUMAH SEHAT}

\section{Arti rumah sehat}

Arti dari permukiman sehat adalah tempat dimana penghuni rumah tersbut merasa nyaman dan tidak terpengaruh dengan lingkungan yang baik dan mendukung. Alur yang dapat digambarkan bahwa tempat tinggal meemiliki ciri khas dan unik untuk masing-masing jenisnya. Karena itu diperlukan design khusus yang dapat menjamin keterkaitan dan kemudahan dalam akses untuk mendapatkan rumah siap huni tersebut. Arti pentingnya sebagai tempat memulai segala aktifitas keluar rumah dimulai dari rumah ini. Fungsi paling penting adalah agar penghuni terhindar dari berbagai macam serangan penyakit maupun serangan dari binatang buas.

Persyaratan khusus seperti dibawah ini adalah :

- Telah memenuhi kebutuhan fisiologis. Artinya dapat membuat nyaman penghuni didalamnya;

- Dapat memenuhi kebutuhan psikologis. Terbantu dengan kenyaman berpikir serta gangguan dari luar maupun secara terstruktur sangat sistematis;

- Telah memenuhi persyaratan penularan penyakit maksudnya adalah aman nyaman dan terkendali;

- Telah memenuhi persyaratan pencegahan terjadinya accident, maksudnya adalah tempat berlindung dari bahaya lalu lintas kendaraan bermotor bagi tempat huni yang berada dipinggir jalan raya. 
Berikut juga disampaikan tentang ketentuan persyaratan kesehatan rumah siap huni untuk ditempati sebagai berikut:

\section{Bahan bahan bangunan}

Tempat tinggal dihindari bukan disusun dari struktur yang berbahaya jika ditinjau dari segi kesehatan antara lain:

- Terdiri dari debu yang tidak lebih dari $150 \mathrm{mg} / \mathrm{m} 2$;

- Sumber dari bahan asbestos yang $\leq$ 0,5 serat $/ \mathrm{m} 3 / 24$ jam;

- Unsur yang terdiri dari timbal $(\mathrm{Pb})$ tidak $\leq$ dari $300 \mathrm{mg} / \mathrm{kg}$ bahan;

- Bahan konstruksi bangunan perumahan tersebut tidak menimbulkan tumbuhan mikroorganisme sebagai unsur pembentuk sumber penyakit untuk berkembang biak.

3. Komponen dalam menata struktur bentuk ruangan

- Bahan dari lantai yang tidak tembus dari zat cair;

- Tembok dari tempat tinggal layak huni tersebut ada $\mathrm{km} / \mathrm{wc}$ nya, mudah aksesibilitasnya serta terjangkau bahan material pembentuk strukturnya;

- Plafonnya berwarna cerah dan kokoh penggantungnya serta tidak berbahaya bagi penghuni didalamnya;

- Nok dan bumbungan dari struktur perumahan tersebut disarankan tinggi dan terdapat jaringan untuk menangkal kilat maupun petir apabila terjadi cuaca ekstrim;

- Penataan ruangan yang sesuai dengan bentuk fungsi dan kegunaan untuk masing-masing ruangan tersbut sehingga pembagiannya tepat;
- Terdapat kitchen set untuk aktifitas ibu rumah tangga di dapur demi melayani keluarga apabila beristirahat dirumah dan ada cerobong asapnya.

4. Pencahayaan

Unsur cahaya yang menerangi pemukiman terstruktur ini adalah dengan memperhatikan bahwa dilakukan dengan memanfaatkan sinar yang ada disekitar sebagai sumber penerangan dengan konsep selalu sehat dan terarah dalam bentuk yang skematis dan konseptual terstruktur.

5. Kualitas udara

- Temperatur udara pada bangunan rumah siap ditempati berkisar antara 18o C sampai 30o C;

- Sistim pengaturan suhu maupun kelembaban berkisar antara 40 persen sampai 70 persen;

- Kandungan dari gas $\mathrm{SO} 2 \leq 0,10$ ppm/ 24 jam;

- Sirkulasi dari peredaran udara harus berkisar antara 5 x 3/orang;

- Peredaran dari gas CO harus $<100$ ppm/8 jam;

- Untuk kandungan gas formaldehid < $120 \mathrm{mg} / \mathrm{m} 3$.

\section{Ventilasi}

Luas lubang ventilasi alamiah yang permanen minimal 10\% luas lantai.

7. Vektor penyakit

Tidak ada lalat, nyamuk ataupun tikus yang bersarang di dalam rumah.

8. Penyediaan air

- Bagi rumah yang siap untuk ditempati harus ada sumber air bersihnya sekitar 60 liter/hari; 
- Jenis dari air yang siap minum harus higienis dan tidak berwarna maupun tidak berbau serta bening tanpa ada partikel-partikel yang membuat air itu tercemar.

9. Pembuangan Limbah

- Limbah cair yang berasal rumah tangga diusahakan tidak mengganggu sumber air dan tidak menghambat aliran air dalam sumber air bersih yang ada;

- Juga diperhitungkan apakah ada bahan berbahaya yang tidak bisa terurai atau dikenal dengan limbah padat.

10. Kepadatan tempat tinggal dan ukuran ruangan

Dalam menentukan ukuran ruangan adalah memenuhi syarat paling tidak dua orang dewasa bisa menempati ruangan tidur tersbut atau seukuran dengan $8 \mathrm{~m} 2$.

Komponen yang harus dimiliki rumah sehat adalah:

1. Pondasi harus kokoh, artinya struktur bangunan yang kuat itu terletak pada bangunan dasarnya yang berhubungan langsung dengan tanah yaitu pondasi bangunan;

2. Alas lantai harus tidak tembus air dan tidak mengandung air, maksudnya ketinggian lantai adalah kurang lebih sekitar sepuluh $\mathrm{cm}$ dari tanah dan diharuskan $25 \mathrm{~cm}$ dari as jalan kalau bangunan rumah tinggal terebut terletak dipinggir jalan raya;

\section{Aksesibiltas pintu maupun} jendela yang fungsinya adalah tempat sirkulasi udara maupun cahaya dari luar untuk jendela, sedangkan pintu tempat masuk dan keluarnya penghuni rumah tinggal;
4. Tembok dari bangunan ini harus tidak tembus air artinya adalah bangunan dari tembok ini harus kokoh dan terbuat dari konstruksi yang tidak mudah roboh serta permukaan temboknya harus halus dan di finishing dengan menggunakan cat yang berkualitas sehingga bangunan rumah tinggal ini dapat menahan masuknya partikelpartikel halus kedalam rumah;

5. Plafondnya juga harus terbuat dari bahan dan penggantung yang berkualitas artinya bahan ini harus sangat berkualitas sehingga dapat menjamin kenyamanan dari penghuninya, plafond ini bisa terbuat dari gypsum yang bagus sampai anyaman bambu yang sangat sehat sekali;

6. Bahan penutup tempat hunian yang siap ditempati adalah terbuat dari genteng, atap seng maupun asbes tergantung dari kemampuan penghuni dalam mengadakan penutup bangunan tersebut sehingga aman dari hujan, panas maupun pertukaran cuaca yang akhir-akhir ini tidak menentu (Keputusan Menteri Kesehatan Republik Indonesia No. 829/Menkes/SK/VII/1999).

\section{SYARAT-SYARAT RUMAH SEHAT}

\section{a. Pencahayaan alami}

Sumber cahaya adalah matahari. Sinar matahari akan masuk lewat pintu dan lewat jendela. Pintu dan jendela terbuat dari bahan kayu maupun bahan alumunium. Sedangkan pengisi dari jendela adalah dari kaca ataupun jeruji besi. Pada zaman dahulu jeruji diganti dari 
anyaman bambu atau kayu yang di jadikan dengan entuk jeruji kayu yang estetis. Sinar yang melewati jendela tersebut kalau terbuka akan memasukkan sumber cahaya yang membawa nikmat seperti unsur ultravilet yang bermanfaat bagi tubuh manusia.

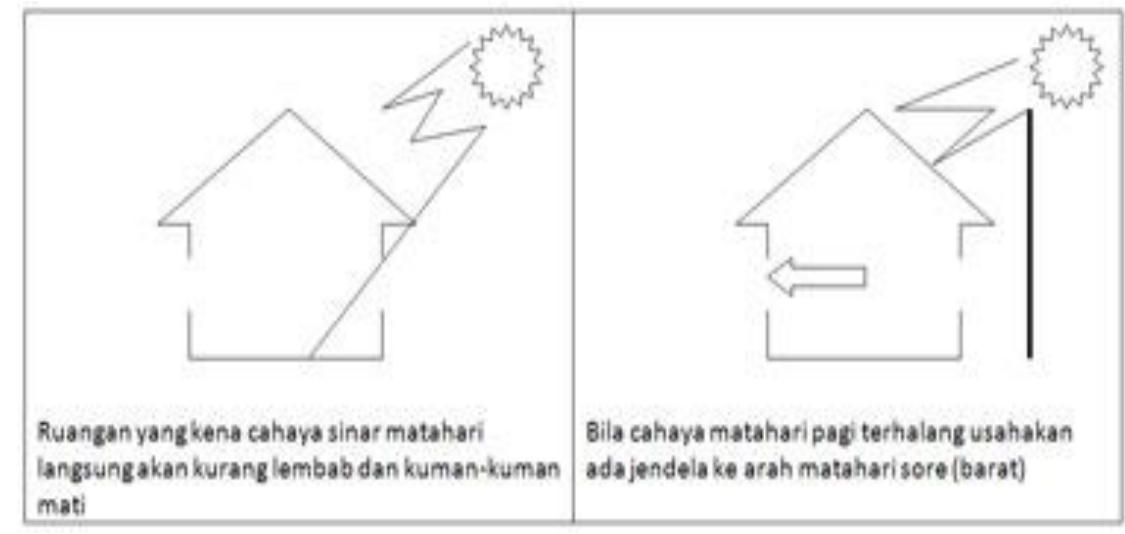

Gambar 1. Sumber cahaya yang menerangi bangunan rumah tinggal

\section{b. Pencahayaan Buatan}

Sumber pencahayaan dibuat dari bangunan yang akan jelas dipengaruhi oleh bermacam cara seperti:

- Pemasangan sumber cahaya terdapat pada tembok dan plafond;

- Bentuk dari konstruksi bangunan terbuat dari bahan yang bermutu;

- Areal dari ruangan dan bentuk yang sangat sistematis;
- Persebaran dari sinar yang masuk kedalam rumah yang siap untuk dihuni adalah yang bermanfaat dan sangat bermutu.

\section{c. Ventilasi (Pertukaran Udara)}

Sirkulasi pertukaran udara yang melewati jendela dan pintu sangat penting. Udara yang penting sangat sehat dan mempunyai temperatur dari $22^{\circ} \mathrm{C}$ sampai $30^{\circ}$

C.

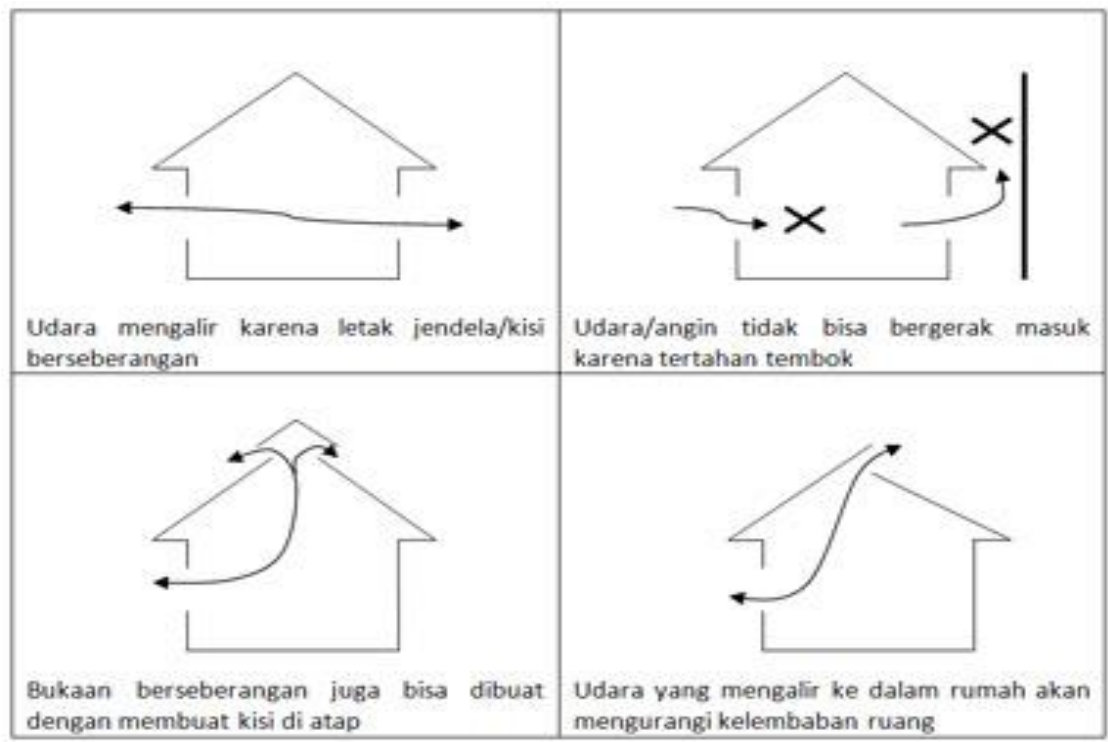

Gambar 2. Sumber masuknya angin yang masuk dan keluar bangunan rumah tinggal 


\section{TINGKAT KELEMBABAN RUMAH TINGGAL}

\section{Pengertian Kelembaban}

Dari jenis kelembaban yang masuk dalam bangunan perumahan siap huni adalah membentuk partikel dalam udara. Negara Indonesia merupakan negara yang tropis sehingga udara ada disekitar kita adalah berbagai musim. Akan tetapi musim yang ada adalah musim panas dan musim pancaroba. Tidak ada musim dingin maupun musim salju di Indonesia.

\section{Pengaruh Tingkat Kelembaban Tinggi}

- Perubahan suhu akan mempengaruhi perubahan pada struktur bangunan tembok dari tempat huni, sehingga dijamin jika adanya perubahan cuaca menyebabkan kerusakan pada bagian-bagian tertentu;
- Strata dari kelembaban juga dipengaruhi oleh jenis dan type dari pintu maupun type dari jendela dan bahan pembentuk jenis jendela itu sendiri terbuat dari yang mudah berubah bentuk maupun ukuran.

\section{Pengaruh Tingkat Kelembaban Rendah}

Perubahan iklim yang terjadi saat ini dipengaruhi oleh musim. Pertukaran dan pergantian musim sangat berpengaruh.

Singkatnya, dalam bentuk karakter maupun kondisi rumah yang siap huni akan sangat berpengaruh pada jenis yang disebutkan dibawah ini:

- KEadaan kelembaban yang ada disekitar lingkungan tempat tinggal yang ditempati;

- Konstruksi bangunan yang ada sudah terlindungi dari lingkungan yang kurang baik

Kebutuhan dari dari keluar masuk penghuni rumah tinggal sangat bergantung pada kondisi lingkungannya.

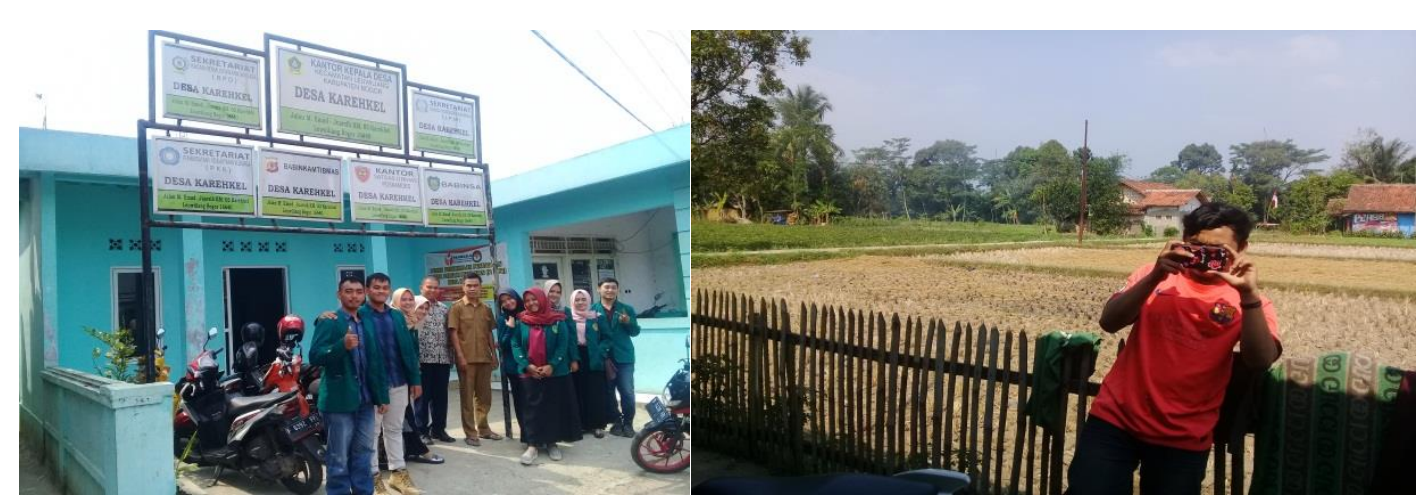

Gambar 3. Sosialisasi pengadaan bangunan tempat tinggal siap untuk dihuni 


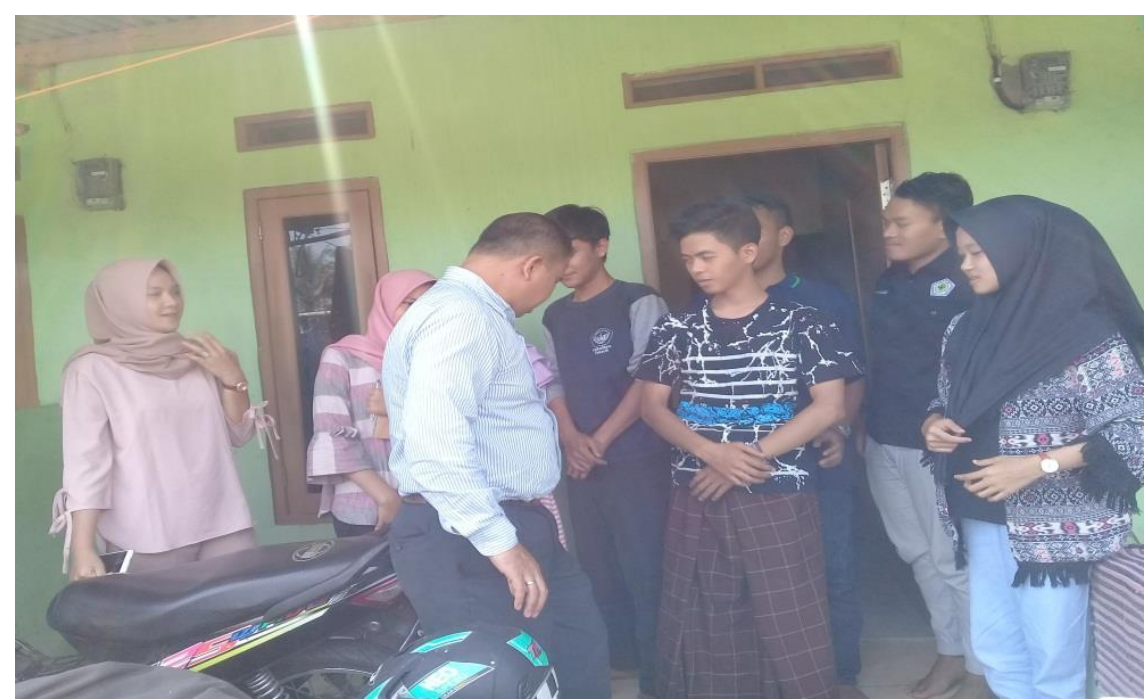

Gambar 4. Hasil dari sosisalisasi perumahan siap huni dan layak

\section{KESIMPULAN}

Dari hasil pembahasan diatas dapat disimpulkan bahwa ada tiga pendekatan yang dipakai dalam program rumah pantas ditempati adalah:

1. Pendekatan di dalam musholla dan masjid serta pengajian;

2. Pendekatan kekerabatan dalam arisan;

3. Pendekatan sosial kemasyarakatan.

Bagi masyarakat kurang mampu
adalah bertambahnya pengetahuan
masyarakat dalam mengelola rumah sehat
dan siap untuk ditempati. Diharapkan
adanya proses perubahan perilaku di
lingkungan masyarakat kurang mampu
agar mereka memahami, mengetahui dan
mampu melakukan perubahan demi
tercapainya masyarakat sehat dan adil
makmur dalam menghuni rumah yang
sangat layak.




\section{DAFTAR PUSTAKA}

Keputusan Kementerian Kesehatan Republik Indonesia, 1999, No. 829/Menkes/SK/VII /1999, Tentang Persyaratan Kesehatan Perumahan, Jakarta.

Undang-undang Nomor 23 Tahun 1992 tentang Kesehatan (Lembaran Negara Tahun 1992 Nomor 100, Tambahan Lembaran Negara Nomor 3495), Jakarta.

Komisi WHO, 2001, Mengenai Kesehatan dan Lingkungan, Jakarta.

Kementerian Pekerjaan Umum dan Perumahan Rakyat (PUPR), 2002, Nomor 403/KPTS/M/2002 tentang Pedoman Teknis Pembangunan Rumah Sederhana Sehat.

Lawuning Nastiti, 2016, Implementasi Program Rehabilitasi Rumah Tidak Layak Huni di Kabupaten Magetan, Tahun 2014, Jurnal Departemen Politik Pemerintahan Fakultas Ilmu Sosial dan ilmu politik Universitas Diponegoro Semarang.

Mahendra Wijaya, 2010, Kemiskinan dan Pemberdayaan Masyarakat Desa, Jurnal of Rural Development, Vol 1, No. 1, Februari 2010.

Denok Kurniasih, 2011, Kinerja Program Kesehatan dalam Menjangkau Masyarakat Miskin: Studi Tentang kapasitas Manajemen dalam Program Jaminan Kesehatan Masyarakat (JAMKESMAS) untuk Keluarga Miskin di Kabupaten Banyumas, Jurnal Sosiohumaniora, Vol. 13, 2, Juli 2011, Purwokerto.
Nunung Nurwati, 2008, Kemiskinan: Model Pengukuran, Permasalahan dan Alternatif Kebijakan, Jurnal Kependudukan Padjajaran, Vol. 10, No. 1 Januari 2008.

SYAIFUL, Syaiful; ELVIRA, Yena. 2017. Case Study On Use Area Parking At New Market City Shopping Center Bogor. IJTI (International Journal Of Transportation And Infrastructure), [S.1.], v. 1, n. 1, p. 34-40, sep. 2017. ISSN 2597-4769. Available at: $<$ http://jurnal.narotama.ac.id/index.p hp/ijti/article/view/330>. Date accessed: 25 jan. 2018. doi: https://doi.org/10.29138/ijti.v1i1.330

SYAIFUL, SYAIFUL (2005) ANALISIS KEBISINGAN ARUS LALU LINTAS DAN GEOMETRI JALAN DI KAWASAN SIMPANG LIMA KOTA SEMARANG. Masters thesis, program Pascasarjana Universitas Diponegoro. Diponegoro University, INSTITUTIONAL REPOSITORY. 